\title{
Periampüller bölge tümörlerinin tanısında papil biyopsisi ve endoskopik görünümün rolü: tek merkez deneyimi
}

\author{
Role of endoscopic biopsy and endoscopic view in diagnosis of periampullary area tumors
}

Ufuk Barış KUZU, Bülent ÖDEMIŞ, Erkan PARLAK, Selçuk DişiBEYAZ, Mustafa KAPLAN, Zeliha SIRTAŞ, Hakan YILDIZ, Nuretdin SUNA, Erkin ÖZTAȘ, Vedat ERKAN, Orhan COŞKUN, Ertuğrul KAYAÇETIN

Türkiye Yüksek ihtisas Eğitim ve Araştırma Hastanesi, Gastroenteroloji Kliniği, Ankara

\begin{abstract}
Giris ve Amaç: Periampuller bölge tümörleri tüm gastrointestinal malignensilerin yaklaşık \%0,5-2'sini oluşturmaktadır. Bu tümörler arasında en sık olarak pankreas bașı ve ampulla vateri kanseri görülmektedir. Bu tümörlerin erken tanısı ve benign lezyonlardan ayırımı tedavi şeklinin belirlenmesinde önem taşımaktadır. Calıșmamızın amacı, papiller forseps biyopsinin pankreas tümürü ve ampulla vateri tümörü tanısında etkinliğinin değerlendirilmesi ve iki tümöre ait özelliklerin karșılaștırılmasıdır. Gereç ve Yöntem: Calıșma Türkiye Yüksek thtisas Hastanesi endoskopik retrograd kolanjiopankreatografi ünitesinde 7 yllhk periyotta endoskopik retrograd kolanjiopankreatografi yapılan ve papiller forseps biyopsisi alınan hastalar geriye yönelik tarandı. Bulgular: Çalışmaya toplam 135 hasta dahil edildi. Toplam 58 (\%50) hastada malignite tespit edildi. En sık saptanan malign tümörler ampulla vateri kanseri ve pankreas bașı kanseri idi [sırası ile hastaların \%28.4 (n=33) ve \%12.1 (n=14)]. Papiller forseps biyopsinin periampuller bölge tümörü tanısında spesifitesi \%96.7 ve sensitivitesi \%72.4 ölçüldü. Papilin endoskopik görünümüne göre endoskopistin yorumunun periampuller bölge tümörü tanısında sensitivitesi \%64.3 olarak ölçüldü. Pankreas başı kanseri ile ampulla vateri kanseri arasında hastalarnn verileri iki kanser grubu arasında karșlastırldığında sadece CA-19.9 değerleri iki grup arasında farklıydı (sırası ile $365 \mathrm{U} / \mathrm{ml}$ ve $78 \mathrm{U} / \mathrm{ml} ; p=0.01$ ). Sonuç: Periampuller bölge tümörleri'nin ayııcı tanısında duedonoskop eşliğinde gerçekleștirilen papiller forseps biyopsisi oldukça yararlı bir yöntemdir. Ek olarak malign hastaların ayırımında papilin endoskopi görünümünün değerlendirilmesi ve tümör markırlarının kullanımı ile bu yöntemin etkinliği daha da arttırlabilir
\end{abstract}

Anahtar kelimeler: Papiller forseps biyopsisi; periampuller tümör
Background and Aims: Periampullary area tumors account for about 0.5$2 \%$ of all gastrointestinal malignancies. Malignant tumors of pancreatic head and ampulla vater are the most seen tumors of this region. The early diagnosis of these tumors and separation from benign lesions are important in choosing a treatment modality. The aim of our study is to evaluate the activity of papillary forceps biopsy in the diagnosis of pancreatic and ampulla vater tumors, and to compare the two tumors' properties. Materials and Methods: Patients in whom papillary forceps biopsy was performed were screened retrospectively in the endoscopic retrograde cholangiopancreatography unit of Türkiye Yüksek thtisas Hospital within 7-year period. Results: A total of 135 patients were included in the study. Malignancy was detected in $50 \%$ of patients $(n=58)$. The most frequent malignant tumors were ampulla vater cancer and pancreatic cancer $[28.4 \%$ of patients $(n=33)$; and $12.1 \%(n=14)$, respectively]. The specificity of papillary forceps biopsy in the diagnosis of periampullary area tumors was found to be $96.7 \%$, and sensitivity was $72.4 \%$. When the endoscopist view was evaluated according to the papillary endoscopic appearance, sensitivity was measured as $64.3 \%$. Only CA-19-9 levels were statistically different between pancreatic head cancer and ampulla vater cancer groups ( $365 \mathrm{U} / \mathrm{ml}$ and $78 \mathrm{U} / \mathrm{mL}$, respectively; $p=$ 0.01). Conclusion: Papillary forceps biopsy performed with duodonoscopy is a useful method in the differential diagnosis of periampullary tumors. This method can be further improved by the evaluation of endoscopic apparance of papillae and additionally by using tumor markers.

Key words: Papillary forceps biopsy, periampullary tumors

\section{GİRIS}

Klinik pratikte periampuller bölge tümörleri (PBT) majör papillanın yaklaşık 2 cm'lik çevresinde gelişen malignensiler olarak tanımlanmaktadır. PBT tüm gastrointestinal malignensilerin yaklaşık \%0,5-2'sini oluşturmaktadır. PBT, ampulla vateri, pankreas başı, distal kolanjiosellüler ve duedonum tümörlerinden oluşmaktadır. Bu tümörler arasında en sık olarak pankreas başı ve ampulla vateri kanseri görülmektedir (1-3). PBT'in semptomları ve oluşturdukları klinik bulgular genelde belirsiz ve özgül değildir. Bu hastalarda en sık başvuru şikayeti safra yollarındaki tıkanmaya bağlı olarak gelişen sarılıktır. Bunun dışında kilo kaybı, anemiye bağlı halsizlik veya paraneoplastik sendroma bağlı semptomlarla da başvu- rabilirler (4). PBT'in erken tanısı ve bunların benign lezyonlardan ayırımı tedavi şeklinin belirlenmesinde (cerrahi endikasyon veya paltatif tedavi) kritik önem taşımaktadır (5).

Perkütan yol ile alınan ince iğne aspirasyon biyopsisinin operatör bağımlı olması ve örnekleme için yeterince belirgin bir lezyon gerektirmesi gibi dezavantajları mevcuttur. Ayrıca cerrahi adayı hastalar için iğne traktına kanser hücrelerinin ekim riski ayrı bir sorun teşkil etmektedir (6). Duedonoskop ile gerçekleştirilen papiller forseps biyopsi'nin (PFB) kolaylıkla yapılabilmesi, güvenli olması ve yaygın kullanımı nedeni ile günümüzde PBT’nin tanısında en sık kullanılan doku örnekleme yöntemidir
Illetişim: Ufuk Barış KUZU Türkiye Yüksek İhtisas Eğitim ve Araştırma Hastanesi, Gastroenteroloji Kliniği, Kızılay Caddesi, 06100, Sıhhiye, Ankara 
Çalışmamızın amacı, PFB'nin pankreas tümürü ve ampulla vateri tümörü tanısında etkinliğinin değerlendirilmesi ve iki tümöre ait temel özelliklerin karşılaştırılmasıdır.

\section{GEREC ve YÖNTEM}

Çalışma Türkiye Yüksek Ihtisas Hastanesi endoskopik retrograd kolanjiopankreatografi (ERCP) ünitesinde gerçekleştirildi. Ocak 2008 - Haziran 2013 tarihleri arasında ERCP işlemi yapilan hastalar geriye yönelik tarandı. Bu süreçte radyolojik veya endosonografik olarak PBT şüphesi nedeni ile PFB yapılan veya başka bir neden ile ERCP yapilırken şüphe nedeni ile PFB yapılan olguların verileri tekrar gözden geçirildi.

Tüm işlemler üç deneyimli endoskopist tarafından Olympus video duodenoskop (Olympus TJF 240 veya JF 240, Tokyo, Japan) ile gerçekleştirilmiştir. PFB tüm vakalarda periampuller bölgeden en az 6 kez endoskopik forseps ile örneğin alınması şeklinde benzer olarak gerçekleştirildi. Her olgunun biyopsi sonuçları yanında demografik özellikleri, görüntüleme yöntemlerinin sonuçları ve merkezimizde kabul edildiği zamanda serumdan çalışılan biyokimyasal parametreleri ile tümör markırları da kaydedildi. Biyokimyasal parametreler total bilirubin (Tbil), aspartat aminotransferaz (AST), alanin aminotransferaz (ALT), alkalin fosfataz (ALP), gama glutamil transferaz (GGT) ve glukozu içermekteydi. Tümör markırı ise karsinoembriyojenik antijen (CEA), alfa fetoprotein (AFP), karbohidrat antijen-19.9 (CA-19.9) ve karbohidrat antijen-125'i (CA-125) içermekte idi. Patolojik sonuçlar homojenite açısından 2 gruba sınıflandırıldı: 1) benign, 2) malign. Benign sonuçlar negatif, malign sonuçlar ise pozitif olarak değerlendirildi.

Çalışmaya kesin olarak malign veya benign tanı alan hastalar dahil edildi. Kesin tanıya, cerrahi ile elde edilen histolojik sonuca göre veya histolojik tanısı olmayan hastalarda en az 12 aylık takip sonucundaki klinik ve radyolojik verilere göre varıldı. Kesin tanısı konulamayan, transpapiller biyopsi sonucu yetersiz olan ve biyopsi ile beraber firça sitolojisi alınan vakalar çalışma dışı bırakıldı.

\section{İstatistiksel Analiz}

Verilerin istatistiksel analizi Statistical Package for Social Sciences (SPSS) version 18 (SPSS Inc., Chicago, IL, United States) bilgisayar program kullanılarak yapıldı. Sürekli değerler alan veriler ortalama ( \pm standart sapma), gerektiğinde ortanca değer (çeyrekler arası aralık; 25.-75. persentiller) olarak, kategorik veriler sıklı ve yüzde olarak $(\mathrm{n}, \%)$ sunulmuştur. Sürekli değerler alan değişkenler için grupların karşlaştırılmasında Student's t-test, kategorik değişkenler için grupların dağılımlarının karşılaştırılmasında Pearson Ki-kare testi ve Fisher'in kesin Ki-kare testi kullanılmıştır. Tip 1 hata düzeyinin \%5'in altında olan durumlar istatistiksel olarak anlamlı kabul edilmiștir

\section{BULGULAR}

Çalışmada toplam 135 hastanın verileri analiz edildi. 19 hasta yetersiz takip veya yetersiz patoloji örneklemesi nedeni ile çalışma dışı bırakııldı. Geriye kalan 116 hasta çalışmaya dahil edildi. Olguların yaş ortalaması 66,9 (23-97) yıldı ve çoğunluğunu kadınlar (\%52.6) oluşturmaktaydı. Final tanıda toplam 58 (\%50) hastada malignite tespit edildi. Bu hastalar içerisinde ampulla vateri kanseri ve pankreas başı kanseri en sık saptanan PBT idi [sırası ile hastaların \%28.4 ( $\mathrm{n}=33)$ ve $\% 12.1(\mathrm{n}=14)$ ]. Finalde benign tanı alan toplam 58 (\%50) hasta mevcuttu. Bu hasta grubu içerisinde en çok nedeni inflamasyon/taşa bağlı yalancı görünüm ve papil adenomu oluşturmaktaydı [sırası ile \%36.2 (n=42) ve \%13.8 ( $\mathrm{n}=16)$ ].

Final tanısı malign olan 58 hastanın 35 'inde (\%60.3) kesin tanı operasyon sonucu alınan dokunun histopatolojik değerlendirilmesi ile teyit edilirken geri kalan 23 hastada tanı radyolojik görüntüleme ve hastaların kliniğine göre teyit edil-

\section{Tablo 1. Hastaların temel özellikleri}

\begin{tabular}{|c|c|}
\hline Hasta sayısı & 116 \\
\hline Yaş (yıl) & $66.9 \pm 14.7$ \\
\hline Erkek/kadın & $55(47.4) / 61(52.6)$ \\
\hline \multicolumn{2}{|l|}{ Final tanı } \\
\hline \multicolumn{2}{|l|}{ Malign } \\
\hline Pankreas başı kanseri & $14(\% 12.1)$ \\
\hline Ampulla vateri tümörü & $33(\% 28.4)$ \\
\hline Tanımlanamamış/diğer & $9 / 2(\% 9.5)$ \\
\hline \multicolumn{2}{|l|}{ Benign } \\
\hline $\begin{array}{l}\text { Taşa bağlı yalancı } \\
\text { görünüm/Inflamasyon }\end{array}$ & $42(36.2)$ \\
\hline Adenom & $16(13.8)$ \\
\hline \multicolumn{2}{|l|}{ Laboratuvar bulguları } \\
\hline Glukoz(mg/dl) & $114 \pm 45.4$ \\
\hline $\operatorname{ALT}(\mathrm{U} / \mathrm{L})$ & $71(7-677)$ \\
\hline AST (U/L) & $66(7-480)$ \\
\hline GGT (U/L) & $303(9-2281)$ \\
\hline ALP (U/L) & $304(37-3100)$ \\
\hline T.bil (mg/dl) & $3(0.2-39.4)$ \\
\hline \multicolumn{2}{|l|}{ Tümör markırları } \\
\hline $\operatorname{AFP}(\mathrm{U} / \mathrm{ml})$ & $2(0.3-6.1)$ \\
\hline CA-19.9 (U/ml) & $56(0.5-2068)$ \\
\hline CA $125(\mathrm{ng} / \mathrm{ml})$ & $13.8(3.2-2623)$ \\
\hline CEA (ng/ml) & $2.5(0.4-312)$ \\
\hline
\end{tabular}

ALT; alanin aminotransferaz, AST; aspartat aminotransferaz, GGT; gama glutamil transferaz, ALP; alkalin fosfataz, T. bil; total bilirubin, AFP; alfa fetoprotein, CA; karbohidrat antijen, CEA; karsinoembriyonejik antijen 
di. Opere olan 35 hastanın tanıları sırası ile ampulla vateri tümörü $(n=27)$, pankreas başı kanseri $(n=5)$, nöroendokrin tümördü ( $\mathrm{n}=1) ; 2$ hastada ise histolojik örneklemeye göre malign tanısı konmasına rağmen spesifik kanser tiplendirilmesi yapılamadı. Malignite tanısı alan 58 hasta içerisinde, 42 hastanın biyopsi sonucu pozitif iken 16 hastada yanlış negatif idi. Benign tanı alan 58 hastada ise 56 doğru negatif varken 2 olguda hafif displaziye bağlı yanlış pozitif sonuç bulunmaktaydı. PFB'nin PBT tanısında spesifitesinin oldukça yüksek (\%96.7) ancak sensitivitesinin kısmen düşük olduğu görüldü (\%72.4) (Tablo 2). Spesifik alt kanser tipleri değerlendirildiginde, PFB sonucu ampulla vateri karsinomu tanısı alan 33 hastanın 27'sinde pozitif ve 6'sında negatif idi; sensitivitesi \%81.8 idi. Pankreas tümörü tanısı alan 14 hastanın 9'ında sonuç pozitif ve 5 hastada negatif idi; sensitivitesi \%64.3 olarak ölçüldü (Tablo 2).

Papilin endoskopik görünümüne göre endoskopistin yorumu değerlendirildiğinde malign tanı olan 58 hastadan 52'sinde tanı doğrulanırken 6 hastada ise negatif yorum bulunmaktaydı. Endoskopistin yorumunun PBT tanısında sensitivitesi \%89.6 ölçüldü.

Malign ve benign hasta grupları arasında Tablo l'deki değişkenler karşılaştırıldığında hastaların demografik özellikleri arasında fark olmadığı izlendi. Ancak glukoz dışındaki laboratuvar bulgularmın malign hastalarda istatistiksel olarak daha yüksek düzeylerde olduğu saptandı $(\mathrm{p}<0.05)$. Benzer şekilde AFP dışındaki diğer tümör markırları da malign hasta grubunda benign hastalara göre belirgin şekilde yüksekti (Tablo 3). Bu farklllik en belirgin olarak CA-19.9'da saptanırken $(\mathrm{p}<0.001)$, bunu sirası ile CEA $(\mathrm{P}=0.01)$ ve $\mathrm{CA}-125$ $(\mathrm{P}=0.04)$ izlemekteydi.

Pankreas başı ile ampulla vateri kanseri arasında hastaların demografik özellikleri ve laboratuvar bulguları değerlendirildiğinde ise iki kanser grubu arasında tüm değişkenler içerisinde istatistiksel farkın sadece CA-19.9'da olduğu görüldü (sırası ile $365 \mathrm{U} / \mathrm{ml}$ ve $78 \mathrm{U} / \mathrm{ml} ; \mathrm{p}=0.01$ ).

Tablo 2. Papil forseps biyopsisinin periampuller bölge tümörlerindeki tanısal bașarısı

\section{Tüm Periampuller Tümörler}

Sensitivite \%

Spesifite \%

PPD \%

NPD \%

Doğruluk oranı \%
(42/58) 72.4

$(56 / 58) 96.7$

(42/44) 95.5

(56/72) 77.8

(98/116) 84.5
Pankreas Başı Kanseri

(9/14) 64.3

(57/58) 98.2

(9/10) 90

$(45 / 51) 88.2$

(66/72) 91.6
Ampulla Vateri Kanseri

(27/33) 81.8

(57/58) 98.2

(27/28) 96.4

(57/63) 90.5

(84/91) 92.3

PPD; pozitif prediktif değer, NPD; negatif prediktif değer.

Tablo 3. Malign ve benign hastalar arasındaki demografik özellikler ve laboratuvar bulgularının karşılaștırılması

\begin{tabular}{|c|c|c|c|}
\hline & Malign Hastalar $(\mathrm{n}=58)$ & Benign Hastalar $(\mathrm{n}=58)$ & P değeri \\
\hline Yaş & $67 \pm 13.8$ & $66.8 \pm 15.6$ & 0.715 \\
\hline Cinsiyet E/K (\%) & $25(43.1) / 33(56.9)$ & $30(51.7) / 28(48.3)$ & 0.353 \\
\hline \multicolumn{4}{|l|}{ Laboratuvar bulguları } \\
\hline Glukoz (mg/dl) & $119 \pm 54.1$ & $110 \pm 34.3$ & 0.665 \\
\hline $\operatorname{ALT}(\mathrm{U} / \mathrm{L})$ & $103(13-677)$ & $44(7-552)$ & 0.006 \\
\hline AST (U/L) & $76.5(11-438)$ & $30.5(7-480)$ & 0.004 \\
\hline GGT (U/L) & $363(12-2163)$ & $241(9-22819$ & 0.004 \\
\hline ALP (U/L) & $398(76-1420)$ & $231(37-3100)$ & 0.001 \\
\hline T. bil (mg/dl) & $10.1(0.3-34.1)$ & $1.15(0.2-39)$ & $<0.001$ \\
\hline \multicolumn{4}{|l|}{ Tümör markırları } \\
\hline $\operatorname{AFP}(\mathrm{U} / \mathrm{ml})$ & $2.1(0.5-6.1)$ & $2(0.3-4)$ & 0.931 \\
\hline CA-19.9 (U/ml) & $139(2-2068)$ & $28.8(0.5-1900)$ & $<0.001$ \\
\hline CA 125 (ng/ml) & $18.2(3.2-2613)$ & $10(3.8-43.8)$ & 0.04 \\
\hline CEA (ng/ml) & $3(0.5-21.1)$ & $2.3(0.4-312)$ & 0.01 \\
\hline
\end{tabular}

ALT; alanin aminotransferaz, AST; aspartat aminotransferaz, GGT; gama glutamil transferaz, ALP; alkalin fosfataz, T. bil; total bilirubin, AFP; alfa fetoprotein, CA; karbohidrat antijen, CEA; karsinoembriyonejik antijen 
Tablo 4. Demografik özellikler ve laboratuvar bulgularının ampulla vateri kanseri ve pankreas başı kanseri arasında karşılaștırılması

\begin{tabular}{|lccc|}
\hline & Ampulla Vateri Tümörü (n:33) & Pankreas Başı Kanseri (n:14) & P değeri \\
\hline Yaş & $64.7 \pm 12$ & $71 \pm 14.7$ & 0.259 \\
\hline Cinsiyet E/K (\%) & $15(45.4) / 18(54.5)$ & $6(42.9) / 8(57.1)$ & 0.870 \\
\hline Laboratuvar bulguları & $101(63-372)$ & $103(72-224)$ & 0.364 \\
\hline Glukoz(mg/dl) & $46(7-552)$ & $93.5(22-677)$ & 0.7270 \\
\hline ALT (U/L) & $66(13-327)$ & $83.5(28-438)$ & 0.499 \\
\hline AST (U/L) & $287(46-2163)$ & $541(85-1221)$ & 0.231 \\
\hline GGT(U/L) & $383(84-1420)$ & $467(170-1320)$ & 0.436 \\
\hline ALP (U/L) & $10(0.3-34.1)$ & $14.1(0.7-28)$ & 0.149 \\
\hline Tümör markırları & & & 0.790 \\
\hline AFP(U/ml) & $2(0.5-4.5)$ & $1.95(1-4.3)$ & 0.01 \\
\hline CA-19.9 (U/ml) & $78(2-1629)$ & $365(16-2068)$ & 0.315 \\
\hline CA 125 (ng/ml) & $13.5(3.2-2613)$ & $21.7(9-172)$ & 0.202 \\
\hline CEA (ng/ml) & $2.4(0.5-8.9)$ & $3.1(1.8-6.5)$ & \\
\hline
\end{tabular}

ALT; alanin aminotransferaz, AST; aspartat aminotransferaz, GGT; gama glutamil transferaz, ALP; alkalin fosfataz, AFP; alfa fetoprotein, CA; karbohidrat antijen, CEA; karsinoembriyonejik antijen

\section{TARTIŞMA}

Pankreatikobiliyer bölge tümörlerinin tanısı genellikle görüntüleme yöntemleri ve doku örneklemesinin kombinasyonu yoluyla konulmaktadır. Manyetik rezonans veya bilgisayarlı tomografi (BT) gibi görüntüleme yöntemleri lezyon hakkında fikir verseler de kesin tanıy teyit edememektedirler (7). ERCP hem safra yollarının görüntülenmesinde hem de gerekli doku örneklerinin alınmasına imkan vermektedir. Bu nedenle günümüzde PBT'nin tanısında önemli rol almaktadır. Daha da önemlisi ERCP ile kitlesel basiya ya da invazyonuna ikincil gelişen biliyer obstrüksiyonlarda tedavi edici işlemler de yapılmaktadır (8). Ek olarak duedonoskopi ile alınan PFB'nin BT gibi radyolojik görüntüleme yöntemlerine göre tanısal başarısı daha yüksektir (9). Daha önce yapılan çalışmalarda PFB'nin PBT tanısında sensitivitesi \%21-81.9 ve spesifitesi \%95-100 arasında bildirilmiş olup çalışmamız sonucu ile bu değerler uyumluydu (10-13).

Papilin endoskopik görünümüne göre endoskopistin yorumunun malignite tanısında tanısal başarısı PFB'e göre daha yüksekti (sırası ile \%89.6 ve \%72.4). Benzer sonuç daha önce De Oliveira ve ark. tarafından da bildirilmiştir. Bu çalışmada 30 PBT tanısı olan hastanın 26'sında (\%87) endoskopik görünüm olarak malignensi tanısı doğrulanmış ve sensitivesi \%87 olarak bildirilmiştir. Aynı çalışmada PFB'nin sensitivitesi ise daha düşük oranda \%65 olarak saptanmıştır (12).

PFB'nin PBT'in alt tiplerindeki tanısal başarısı incelendiğinde beklenildiği üzere ampulla vateri kanserindeki tanısal etkinliği pankreas başı kanserine göre daha yüksekti. Ampulla vateri malignensilerinin büyük çoğunluğunu adenokarsinom oluşturmaktadır ve insidansı ileri yaşlarda pik yapmaktadır. Epitelyal malignensilerin yaklaşı \%l'ni ve tüm gastrointestinal malignensilerinin de yaklaşık \%5'ini oluşturmaktadır. Anatomik yerleşim yeri özelliklerinden dolayı erken belirti verdiklerinden dolayı pankreas başı kanserinin aksine prognozu daha iyidir ve tanı anında hastaların büyük çoğunluğunda tümör cerrahi olarak çıkarılabilmektedir (14). Ampulla vateri tümörü dahil PBT'inde standart pankreatikoduodenektomi tedavi şekli olarak kabul edilmekle beraber günümüzde pilor koruyucu pankreatikoduodenektomi genel prosedür haline gelmeye başlamıştır (15). Bizim serimizde de literatür ile uyumlu olarak hastaların büyük çoğunluğu 60 yaş üzerindeydi ve bu hastaların \%81.9'unun operasyona uygun olduğu gözlendi.

Pankreas başı kanseri tüm kanserler içerisinde en sık görülen dördüncü kanserdir. Tüm pankreas kanserlerinin yarısından fazlası pankreas başında meydana gelmektedir. Histolojik olarak pankreas kanserlerinin \%90'ından fazlasını duktal hücrelerden kaynaklanan adenokarsinomlar oluşturmaktadır. Ampulla vateri kanseri gibi ileri yaşlarda daha sık gözlenmekte olup prognozu daha kötüdür $(16,17)$.

Çalışmamız sonucunda benign ve malign tanısı olan hastalar arasında karaciğer biyokimyasal testleri ve AFP dışındaki tümör markırları arasında anlamlı fark saptandı. Bu laboratuvar değerlerindeki yükseklik daha önce de bildirilmiş olup muhtemel olarak maligniteye bağlı bulguların daha şiddetli 
bir tabloya neden olmasından kaynaklı olabileceği öne sürülmüştür (18). Ek olarak CEA, CA-19.9 ve CA-125 gibi tümör markırlarının pankreatikobiliyer bölgedeki malign tümörlerin benign lezyonlardan ayırımında kullanılabileceği birçok çalışmada gösterilmiş olup çalışmamız sonucu da bu verileri desteklemektedir (18-20).

Pankreas başı kanseri ve ampulla vateri kanseri olan hastalar arasında sadece CA-19.9 değeri anlamlı olarak farklıydı. CA-19.9 glikoprotein yapıda olup çeşitli epitelyal kanserlerin yanı sıra normal pankreas ve safra kanalında da salgilanmaktadır. Ilk olarak 1979 yllında Koprowski tarafından tanımlanmış olup günümüzde pankreatikobiliyer bölge malignensiler için yararlı bir tümör markırı olarak kullanılmaktadır (21). Ancak maligniteler dışında safra yollarının benign hastalıklarında da serum kansantrasyonu yükselebilmesi bu markırın kullanımında en önemli dezavantajdır (18,19). Literatürde

\section{KAYNAKLAR}

1. Uomo G. Periampullary carcinoma: some important news in histopathology. JOP 2014;15:213-5.

2. Berberat PO, Kunzli BM, Gubinas A, et al. An audit of outcomes of a series of periampullary carcinomas. Eur J Surg Oncol 2009;35:187-91.

3. Beger HG, Treitschke F, Gansauge F, et al. Tumor of the ampulla of Vater: Experience with local or radical resection in 171 consecutively treated patients. Arch Surg 1999;134:526-32.

4. Hutchins R, Williamson RCN. Periampullary Cancer. Medicine. 2003;31(3): 126-7.

5. Leese T, Neoptolemos JP, West KP, et al. Tumours and pseudotumours of the region of the ampulla of Vater: an endoscopic, clinical and pathological study. Gut 1986;27:1186-92.

6. Warshaw AL. Implications of peritoneal cytology for staging early pancreatic cancer. Am J Surg 1991;161:26-9.

7. Barish MA, Yucel EK, Ferrucci JT. Magnetic resonance cholangiopancreatography. N Engl J Med 1999;341:258-64

8. Cohen S, Bacon BR, Berlin JA, et al. National Institutes of Health Stateof-the-Science Conference Statement: ERCP for diagnosis and therapy, January 14-16, 2002. Gastrointest Endosc 2002;56:803-9.

9. Griffanti-Bartoli F, Arnone GB, Ceppa P, et al. Malignant tumors in the head of the pancreas and the periampullary region. Diagnostic and prognostic aspects. Anticancer Res. 1994;14:657-66.

10. Sugiyama M, Atomi Y, Wada N, et al. Endoscopic transpapillary bile duct biopsy without sphincterotomy for diagnosing biliary strictures: a prospective comparative study with bile and brush cytology. Am J Gastroenterol 1996;91:465-7.

11. Pugliese V, Conio M, Nicolò G, et al. Endoscopic retrograde forceps biopsy and brush cytology of biliary strictures: a prospective study. Gastrointest Endosc 1995;42:520-6.

12. DeOliveira ML, Triviño T, de Jesus Lopes Filho G. Carcinoma of the papilla of Vater: are endoscopic appearance and endoscopic biopsy discordant? J Gastrointest Surg 2006;10:1140-3.
CA-19.9'un pankreas kanseri ayırıcı tanısında belirteç olarak veya PBT'inde prognostik faktör olarak kullanılabileceğini gösteren birçok çalışmalar bildirilmiştir $(19,20,22)$. Prognozu farklı olan bu 2 kanserin ayırımında kullanılabileceğini gösteren benzer çalışma Böttger ve ark. tarafından bildirilmiştir. Çalışmamız sonucuna paralel şekilde bu çalışmada CA-19.9 değeri pankreas başı kanseri olan hastalarda diğer PBT’lere göre anlamlı olarak daha yüksek düzeyde olduğu ve daha iyi sensitiviteye sahip olduğu saptanmıştır (23).

Sonuç olarak, periampuller bölge tümörlerinin ayırıcı tanısinda duedenoskop eşliğinde gerçekleştirilen PFB oldukça yararlı bir yöntemdir. Ek olarak malign hastaların ayırımında papilin endoskopi görünümünün değerlendirilmesi ve tümör markırlarının kullanımı ile bu yöntemim etkinliği daha da arttırılabilir.

13. Menzel J, Poremba C, Dietl KH, et al. Tumors of the papilla of Vater--inadequate diagnostic impact of endoscopic forseps biopsies taken prior to and following sphincterotomy. Ann Oncol 1999;10:1227-31.

14. Ross WA, Bismar MM. Evaluation and management of periampullary tumors. Curr Gastroenterol Rep 2004;6:362-70.

15. Sakorafas GH, Friess H, Balsiger BM, et al. Problems of reconstruction during pancreatoduodenectomy. Dig Surg 2001;18:363-9.

16. Schima W, Ba-Ssalamah A, Kolblinger C, et al. Pancreatic adenocarcinoma. Eur Radiol 2007;17:638-49.

17. Jemal A, Siegel R, Ward E, et al. Cancer statistics, CA Cancer J Clin 2008;58:71-96.

18. Kuzu UB, Ödemiş B, Turhan N, et al. The diagnostic value of brush cytology alone and in combination with tumor markers in pancreaticobiliary strictures. Gastroenterol Res Pract 2015;2015:580254.

19. Cwik G, Wallner G, Skoczylas T, et al. Cancer antigens 19-9 and 125 in the differential diagnosis of pancreatic mass lesions. Arch Surg 2006;141:968-74.

20. Morris-Stiff G, Teli M, Jardine N, Puntis MC. CA19-9 antigen levels can distinguish between benign and malignant pancreaticobiliary disease. Hepatobiliary Pancreat Dis Int 2009;8:620-6.

21. Koprowski H, Steplewski Z, Mitchell K, et al. Colorectal carcinoma antigens detected by hybridoma antibodies. Somatic Cell Genet 1979;5:95771.

22. Alexakis N, Gomatos IP, Sbarounis S, et al. High serum CA 19-9 but not tumor size should select patients for staging laparoscopy in radiological resectable pancreas head and peri-ampullary cancer. Eur J Surg Oncol 2015;41:265-9.

23. Böttger T, Hassdenteufel A, Boddin J, et al. Value of the CA 19-9 tumor marker in differential diagnosis of space-occupying lesions in the head of the pancreas. Chirurg 1996;67:1007-11. 